\title{
Posterior longitudinal ligaman ossifikasyonu: prevalans, prezentasyon ve doğal seyir
}

\section{Ossification of the posterior longitudinal ligament: prevalence, presentation and natural history}

\author{
Yunus Atıcı ${ }^{1}$, Barış Polat ${ }^{2}$ \\ ${ }^{1}$ Okan Üniversitesi Tıp Fakültesi, Ortopedi ve Travmatoloji Anabilim Dalı, İstanbul, Türkiye \\ ${ }^{2}$ Yakın Doğu Üniversitesi Tıp Fakültesi, Ortopedi ve Travmatoloji Anabilim Dalı, Lefkoşa, Kuzey Kıbrıs Türk Cumhuriyeti
}

\begin{abstract}
Daha çok uzak doğu toplumlarında görülen posterior longitudinal ligaman (ligament) ossifikasyonu (PLLO), spinal kanalı daraltarak servikal miyelopati veya radikülopatiye yol açabilen bir durumdur. Ülkemizde nadir görüldüğü ve yeteri kadar tanınmadığı için, bu derlemede PLLO'nun etiyoloji, epidemiyoloji, prezantasyon ve doğal seyrini literatür eşliğinde anlatmayı amaçladık. Çalışmalar, etiyolojisi tam olarak belirlenemeyen bu hastalığın gelişiminde, genetik, çevresel, hormonal ve yaşam tarzı gibi faktörlerin etkili olduğunu göstermiştir. Genellikle 40 yaşından sonra ve erkeklerde daha sık görülen PLLO'nun prevalansı, uzak doğu toplumunda \%2-4 iken Asyalı olmayan toplumlarda \%0,01-2'dir. PLLO, vertebranın her seviyesinde görülmesine rağmen, servikal bölgede en sıktır. Asemptomatik bir tablodan ileri seviye engelliliğe kadar geniş bir spektrumda klinik prezantasyona sahiptir. Tanıda; fizik muayene ile beraber direkt grafiler, bilgisayarlı tomografi (BT) ve manyetik rezonans (MR) görüntüleme kullanılır. Özellikle BT, sınıflama ve ameliyat öncesi planlamada çok değerlidir. Hafif-orta şiddette, semptomatik ve şikayetlerin ilerlemediği hastalarda konservatif tedavi tercih edilirken; miyelopati gelişen, konservatif tedaviden yanıt alınamayan ve ilerleyici semptomları olan hastalarda cerrahi tedavi düşünülmelidir.
\end{abstract}

Anahtar sözcükler: posterior longitudinal ligaman ossifikasyonu; prevalans; prezantasyon; doğal seyir

\begin{abstract}
As a condition commonly reported in Far East countries, ossification of posterior longitudinal ligament (OPLL) is a condition which may cause cervical myelopathy or radiculopathy by narrowing the spinal tract. Since it is not a well-known disease and rarely reported in our country, the objective of this study is to describe the etiology, epidemiology, presentation, and natural history of OPLL accompanied with related literature. Even the etiology of this condition is still not fully determined, the studies demonstrate that factors such as genetics, environmental factors, hormones and lifestyle are effective in the progression of the disease. OPLL is reported more frequently in men and after age 40 and the prevalence of this condition is between $2 \%$ and $4 \%$ in Far East countries, whereas the in non-Asian countries it is between $0.01 \%$ and $2 \%$. Despite the fact that OPLL can be diagnosed in all levels of the vertebra, it is most frequently seen in the cervical region. From asymptomatic conditions to an advanced level of disability, OPLL has a clinical presentation in a broad spectrum. Direct graphy, computed tomography $(C T)$ and magnetic resonance (MR) imaging are used along with physical examination for diagnosis of this condition. Notably, CT has a great value in classification and pre-operative planning. While a conservative treatment is preferred for patients with mild to moderate symptomatic or non-progressive disease, surgical treatment should be considered for patients with progressive symptoms who do not respond to conservative treatment.
\end{abstract}

Key words: ossification of posterior longitudinal ligament; prevalence; presentation; natural history
P osterior longitudinal ligaman (ligament), spinal kanalın ön, vertebra gövdesinin arka yüzünde bulunur; oksiputtan sakruma kadar uzanır. Omurganın aşırı fleksiyonunu engelleyerek stabiliteye katkı sağlayan omurganın en önemli ligamanlarındandır. Bu ligamanda hipertrofi ve ossifikasyon gelişmesi, spinal kanalı daraltarak servikal miyelopati ve/veya radikülopatiye yol açabilmektedir. ${ }^{[1-5]}$ Daha çok Uzak Doğu toplumlarında görülen bu hastalığın oluşumunda birçok çevresel ve genetik faktör tanımlanmasına rağmen, araştırmalar devam etmektedir. Ülkemizde nispeten nadir görülmesi ve yeteri kadar tanınmaması nedeniyle göz ardı edilebilmektedir. Bu derlemede PLLO'nun

- İletişim adresi: Okan Üniversitesi Hastanesi, İçmeler mah. Aydınlı yolu cad. Aydemir sok. No:2, Tuzla, İstanbul Tel: 0505 - 4921945 e-posta: yunatici@hotmail.com

- Geliș tarihi: 5 Nisan $2017 \quad$ Kabul tarihi: 5 Nisan 2017 
etiyoloji, epidemiyoloji, prezantasyon ve doğal seyrine değinilecektir.

\section{ETIYOLOJi}

PLLO'nun nasıl başladığı ve ilerlediği halen kesin olarak ortaya konulmamıştır. Çalışmalar, hastalığın gelişiminde genetik, çevresel, hormonal ve yaşam tarzı gibi faktörlerin etkili olduğunu göstermiştir. Yüksek vücut kitle indeksi ${ }^{[6]}$, insülin ve diyabet ${ }^{[7]}$, glukoz intoleransı ve obezite ${ }^{[8]}$, miyotonik distrofi ${ }^{[9]}$, vitamin D'ye direçli rikets gibi endokrin hastalıklar ${ }^{[10]}$, yüksek tuz - düşük et diyeti, düşük kalsiyum absorpsiyonu, uzun çalışma saatleri, gece vardiyasında çalışmak ve ligaman üzerinde aşırı mekanik stres oluşmasının ligaman ossifikasyonunu arttırdığı gösterilmiştir. PLLO, enkondral kemikleşme ile benzer bir yol izler. Kondrosit diferasyonu, osteoblast formasyonu ve kartilaj dokunun kemik dokuya dönüşmesi olan enkondral kemikleşme aşamalarında görevli büyüme ve/veya transkripsiyon faktörlerindeki mutasyonların da ossifikasyonu hızlandırdığı gösterilmiştir. Genlerdeki mutasyonların, tek nükleotid polimorfizminin ve haplotiplerin de etiyolojide önemli yer tuttuğu bilinmektedir. Runx2 polimorfizim ${ }^{[11]}$, RSPO2 geni (Wnt- $\beta$ catenin sinyali kodlaması $)^{[12,13]}$, osterix ${ }^{[13]}$, Sox9[14], HAO1 ${ }^{[15]}$ genlerinin aşırı ekspresyonu da ligaman ossifikasyonundan sorumlu tutulmuştur.

\section{EPIDEMIYOLOJisi}

\section{İnsidans}

PLLO, genellikle 40 yaşından sonra görülür. ${ }^{[16]} \mathrm{Bu}$ da, yaşlanma sürecinin ligaman ossifikasyonunda önemli rol oynadığını gösterir. PLLO'nun Uzak Doğu toplumunda prevalansı \%2-4 iken Asyalı olmayan toplumlarda \%0,01 ile \%2 arasında değişen oranlarda görülmektedir. ${ }^{[17]}$ Fujimori ve arkadaşları, 1500 Japon hastanın tümör taraması amacıyla çekilen pozitron emisyon tomografisi/bilgisayarlı tomografi (PET/BT)'lerini geriye dönük incelemişler ve servikal PLLO'nun prevalansını $\% 6,3$ (erkeklerde \%8,3 iken bayanlarda \%3,4), torakal PLLO'nun prevalansını \%1,6, lomber PLLO'nun prevalansını \%0,7 olarak bulmuşlardır. ${ }^{[18]}$ Bu oranların bu kadar yüksek olmasının nedeni, diğer çalışmalardan farklı olarak, bu çalışmada taramanın servikal grafi yerine BT ile yapılmasıdır. Posterior longitudinal ligamanın, anatomik olarak servikal bölgede daha kalın ve geniş iken, lomber bölgeye indikçe daha daralıp incelmesi de PLLO'nun servikal bölgede prevalansının yüksek olmasını açıklamaktadır. ${ }^{[19]}$ Servikal PLLO en sık C5 seviyesinde görülürken, bunu C6 ve C4 takip eder. ${ }^{[18]}$ Yine aynı çalışmada, servikal PLLO olan hastaların \%13'ünde torasik PLLO, \%34'ünde torasik ligamentum flavum ossifikasyonu, \%45'inde nukhal ligaman ossifikasyonu, \%36'sında diffüz idiyopatik iskelet hiperostozunun eşlik ettiği görülmüş̧tür. ${ }^{[18]}$ Bu yüzden, servikal PLLO olan hastada başka ligaman ossifikasyonlarının da eşlik edebileceğini düşünüp, tüm spinal ligaman ossifikasyonlarını değerlendirmemiz gerekmektedir.

\section{PREZANTASYON}

\section{Yaş-Cinsiyet}

PLLO, sıklıkla orta yaş veya yaşlı erkeklerin servikal bölgesinde oluşur. Çocuk ve adolesanlarda rapor edilmemiştir. Kırk yaşından sonra görülme sıklı̆̆ı önemli ölçüde artarken, genellikle 50 yaş üzerinde görülür. Servikal bölgede, erkeklerde sıklığı kadınlardan iki kat daha fazladır. Torasik bölgede, kadınlarda daha sık olsa da bunun nedeni belirsizdir.

\section{Lokasyon}

PLLO, vertebranın her seviyesinde görülmesine rağmen, servikal bölgede en sıktır. Torakal bölgede en sık üst ve orta seviyede görülür. Lomber PLLO nadir görülür ve genellikle şiddetli sakatlığa yol açmaz.

\section{Belirti ve Bulgular}

PLLO, spinal kanalda yol açtığı darlığın şiddeti ve süresiyle orantılı olarak, oldukça geniş spektrumda bir klinik tablo ile karşımıza çıkabilir. Hastalar asemptomatik olabildiği gibi, ileri derecede engelli de olabilir. PLLO olan hastaların çoğu klinik belirti vermez ve asemptomatikdir. Hatta, büyük ossifiye lezyonu olan çoğu hastalarda dahi ileri derecede klinik semptomlar saptanmayabilir. Nörolojik bulgular; miyelopati, radikülomiyelopati veya tek başına radikülopati (nadir) şeklinde olabilir. Hastaların \%80-85'inde bu nörolojik bulgular yavaş progresyon gösterir. Akut başlayan veya agresif seyreden durumlarda ise, sıklıkla minör bir travma veya boynun hiperekstansiyonu mevcuttur. PLLO'nun başlangıcında en yaygın şikayet, elde parestezi veya hissizliktir. Bir başka semptom, elde sakarlıktır. Şikayetler yavaş yavaş alt ekstremiteye ilerler ve yürüme bozukluğu gelişir. Bu nörolojik semptomlara göre üç farklı hasta grubu ile karşılaşırız. Bunlar; alt ekstremitede ağırlıklı nörolojik defisit gelişen, üst ekstremitede ağırlıklı nörolojik defisit gelişen ve nörolojik defisit olmaksızın boyun, omuz ve kollarda ağrı ile seyreden gruplardır.

\section{TANI}

\section{Fiziksel Muayene}

Hastaların çoğunda boyun ağrısı görülür. Radikülopatinin eşlik ettiği hastalarda, boyundan başlayıp omuzlara ve kollara doğru yayılan ağrı, yakınmaların 
önemli kısmını oluşturur. Bu yansıyan ağrılar, Spurling testi (başın ağrıyan tarafa doğru eğdirilip aksiyel yüklenme yapılması) ile arttırılabilir. Radikülopati, foraminal stenoz sonucu, ilgili sinir kökünde bası ile gelişir. Radikülopati tanısında, servikal spinal sinirlerin duyusal, motor ve refleks muayenesi önem taşır.

Spinal kanalın santral stenozu sonucu gelişen miyelopatide ise, ince motor beceride azalma, yürüme ve denge bozuklukları en erken belirtilerdir. Stenozun ilerlemesi ile, hasta yürümek için yardıma ya da tekerlekli sandalyeye ihtiyaç duyabilir. Alt ekstremitede birinci motor nöron bulguları varken; üst ekstremitede sinir kökü bası bulgularına bağlı olarak ikinci motor nöron bulguları görülür. Ayrıca, üst ekstremitede bası düzeyinin altında kalan segmentlerde birinci motor nöron bulguları çıkabilir. Alt ekstremitede sertlik, güçsüzlük, reflekslerde artış ve patolojik refleksler vardır. Arka kolon hasarının eklenmesiyle, alt ekstremitelerde derin duyu bozukluğu, dengesizlik ve ayaklarını aşıı açarak dengeyi bulmaya çalışan spastik yürüme paterni ortaya çıkar. Üst ekstremitede ise, yazı yazmada, şekil çizmede ve düğme iliklemede güçlük vardır. Bası düzeyinde reflekslerde azalma, bası düzeyinin distalinde ise reflekslerde artma beklenir. Ayrıca, patolojik refleksler de görülebilir.

Fizik muayenede boynun fleksiyon ve ekstansiyonu ile yapılan Lhermitte testinde tüm bedenin elektriklenmesi servikal miyelopatiyi gösterir. Rhomberg ve tandem testleri, yürüme ve denge bozukluğunun erken tanısında yardımcı olabilir. Hoffman testi, Babinski, klonus gibi patolojik refleksler de omurilik basısına işaret eder. C3 ve üzerindeki basılarda skapulohumeral refleks pozitiftir. Bu reflekste, spina skapula ya da akromiyona refleks çekici ile vurulduğunda kol abduksiyona gelir. Miyelopatik el bulguları, Hoffman testi, on saniye testi ve parmak kaçma testidir.

Hoffman testinde, hasta gevşemiş pozisyonda elleri serbest bırakarak, bir yandan elinin 3. parmağında metakarpofalangeal, proksimal interfalangeal eklemleri ekstansiyona zorlanırken, aynı anda tırnak üzerinden parmağımızı kaydırarak fleksiyona getirilip bırakma işlemi sırasında 1. ve 2. parmakları refleks şeklinde fleksiyona geliyorsa test pozitiftir.

On saniye testinde, hasta her iki el bileği ve dirseği ekstansiyondayken kollarını omuzdan $90^{\circ}$ fleksiyona getirir. Daha sonra, her iki elini olabildiğince hızlı yumruk yapıp açması istenir. On saniye içinde $14-15$ 'in üzerinde yapması beklenir. Daha yavaş ve beceriksizce yapıyorsa test pozitiftir.

Parmak açma testinde, hasta her iki el bileği ve dirseği ekstansiyondayken kollarını omuzdan $90^{\circ}$ fleksiyona getirir. Tüm parmakların ekstansiyonda ve bir arada tutması istenir. Hasta 5. parmağını adduksiyona getirerek 4. parmağıyla bir arada tutamazsa test pozitiftir. ${ }^{[20,21]}$

\section{Radyolojik Tanı}

\section{Direkt grafi}

Tek başına servikal yan grafi bile PLLO ile ilgili çok fazla bilgi verebilir. lyyi bir inceleme için, dört yönlü (önarka, yan, sağ ve sol oblik) servikal grafilerin çekilmesi gerekir. Direkt grafilerde, servikal yapı diziliminde bozulmalar (artmış lordoz, kifoz, S tipi deformite), spondilotik değişiklikler (disk aralığında daralma, osteofitler, foramenlerde daralma) PLLO'ya eşlik edebilir. Özellikle foramen daralmaları en iyi oblik grafilerde görülebilir. Bu değişiklikler tek seviyede olabileceği gibi, birden fazla seviyede de olabilir. İnstabilite şüphesi olan hastalarda, fleksiyon ve ekstansiyonda lateral servikal grafiler de çekilmelidir.

\section{Bilgisayarlı tomografi (BT)}

Servikal BT, PLLO tanısında direkt grafilere göre daha yüksek güvenilirlikte olması, radyolojik olarak sagittal kesitlerde sınıflamaya olanak vermesi ve cerrahi öncesi planlamadaki yararlarından dolayı rutin olarak önerilmektedir. PLLO'nun BT'de sagittal kesitlerde görünümü, Hirabayashi tarafından dört klasik biçimde tanımlanmıştır (Şekil 1). ${ }^{[22]}$

A: Yalnız disk aralığında yer alan tip.

B: Segmenter: Yalnız omurga gövdeleri arkasında olan tip.

C: Sürekli: Birden fazla omurga gövdesi arkasına yerleşmiş, süreklilik gösteren tip.

D: Karışık: Değişik bölgelerde sürekli ve segmenter tiplerin olduğu tip.

PLLO'ya dural ossifikasyonun da eşlik ettiği durumlarda sınıflama, servikal BT'nin aksiyel kesit görüntülerine göre yapılır (Şekil 2). ${ }^{[23]}$

A: İzole tip: Posterior longitudinal ossifikasyon ile ilişkisiz dural ossifikasyon.

B: Çift katmanlı tip: Posterior longitudinal ossifikasyon ile dural ossifikasyon aynı seviyede ama arada epidural boşluk mevcut.

C: Tek katmanlı tip: Posterior longitudinal ligaman ve duranın aynı seviyede, arada boşluk olmadan en-blok olarak ossifikasyonu.

Bu sınıflamanın cerrahi öncesi planlamada önemi büyüktür. En-blok (tek katmanlı) tipte ossifikasyonların cerrahisinde, anteriordan ossifiye posterior longitudinal ligamanı çıkarırken dural ossifikasyondan titizlikle ayırmak gerekir. Böylece, anterior yaklaşımla ile 


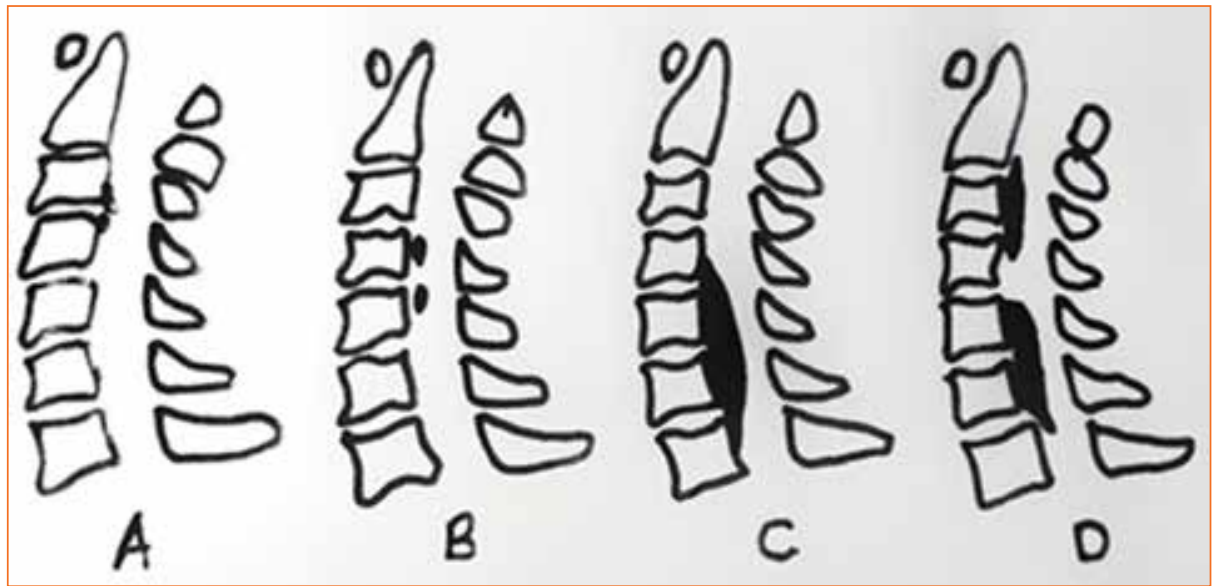

Şekil 1. PLLO'nun BT'de sagittal kesitlerde görünümü.

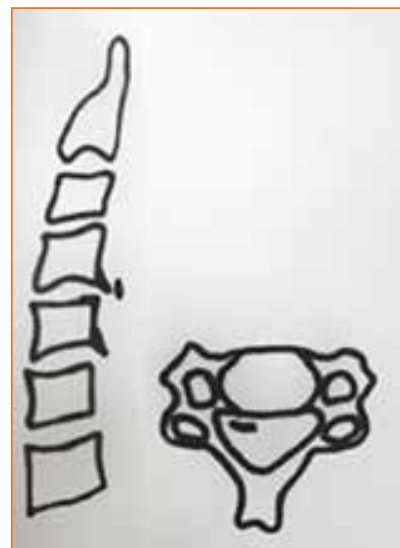

A

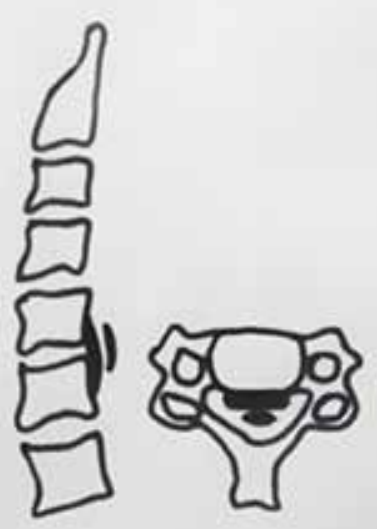

B

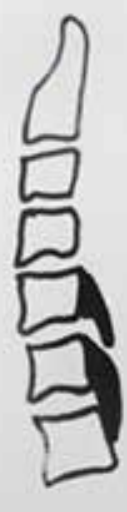

$c$

Şekil 2. Sınıflamanın aksiyel BT’ye göre yapılması.

yapılan cerrahilerde en sık ameliyat içi komplikasyon olan beyin-omurilik sıvısı (BOS) kaçağından korunmuş olunur.

\section{Manyetik rezonans (MR)}

Servikal MR, posterior longitudinal ligaman ossifikasyonunun spinal korda basısı sonucu gelişen miyelomalaziyi tespit etmede ve radikülopatinin eşlik ettiği olgularda foraminal stenozu göstermesi açısından değerlidir.

\section{SEMPTOMATIK ILERLEMEDE RADYOLOJIK RISK FAKTÖRLERI}

Semptomatik ilerlemede birçok radyolojik risk faktörleri tanımlanmıştır. Bunlardan biri olan occupancy oranı, lateral radyografide ya da servikal BT'de darlığın en fazla olduğu bölgedeki kanal çapının spinal kanal çapına bölünmesiyle, yüzde olarak ifade edilir (Şekil 3). Bu oranın \%30-60 olması miyelopati riskini arttırır. Occupancy oranı \%60'dan büyük olan hastaların \%100'ünde miyelopati geliştiğini gösteren çalışmalar mevcuttur. ${ }^{[24,25]}$ Ayrıca, aksiyel BT kesitlerinde PLLO'nun tam santralda değil de yanlarda oluşması (Şekil 4) ile, geniş servikal eklem hareket açıklığına sahip hastalarda miyelopati gelişme riskinin arttığı gösterilmiştir. ${ }^{[24]}$

Kompresyon açısı, sagittal kesit T2 MR incelemede en fazla kompresyona yol açan tepe noktadan proksimalde ve distalde kompresyonun bittiği noktalara doğru çizilen çizgiler arası açıdır (Şekil 3). Lee ve arkadaşları, semptomatik PLLO olan 50 hastayı geriye dönük incelediklerinde, sadece kompresyon açısının orta ve ileri miyelopatilerde anlamlı düzeyde farklı olduğunu bulmuşlardır. ${ }^{[2]}$ 


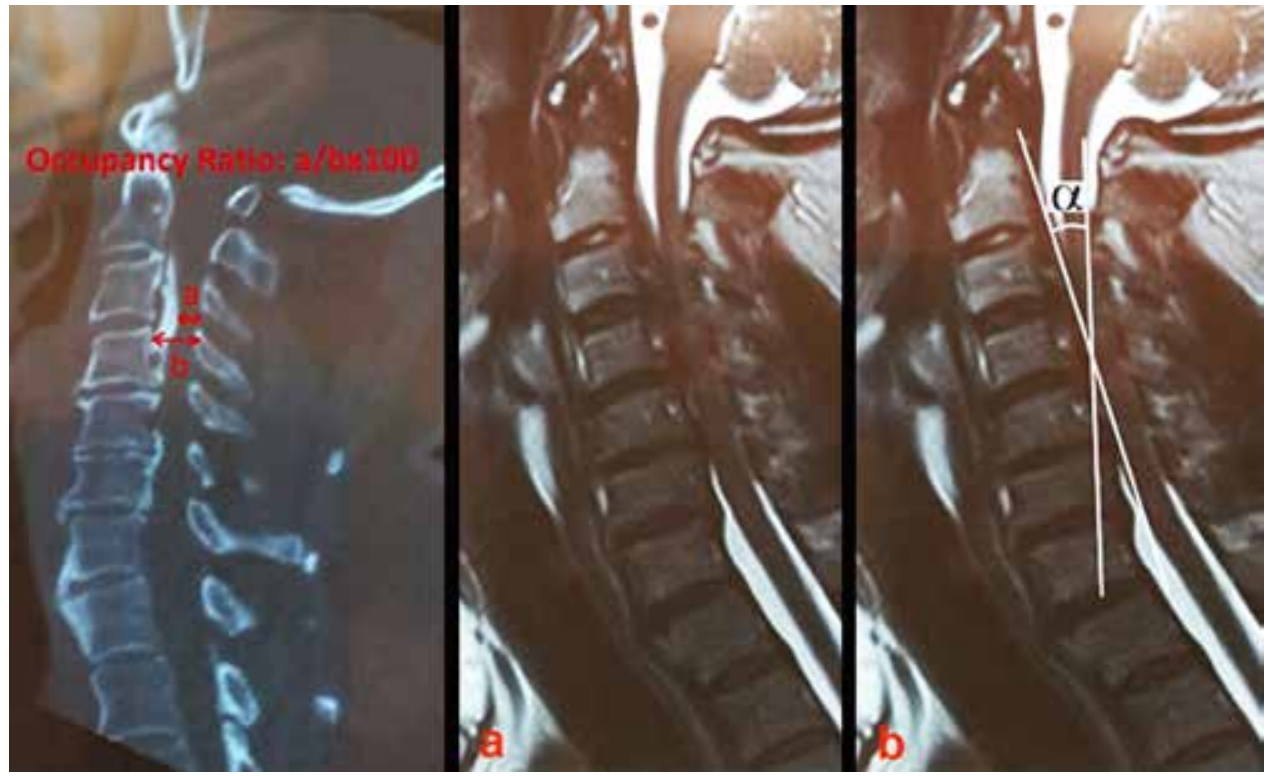

Şekil 3. Occupancy oranı ve kompresyon açısı ölçümleri.
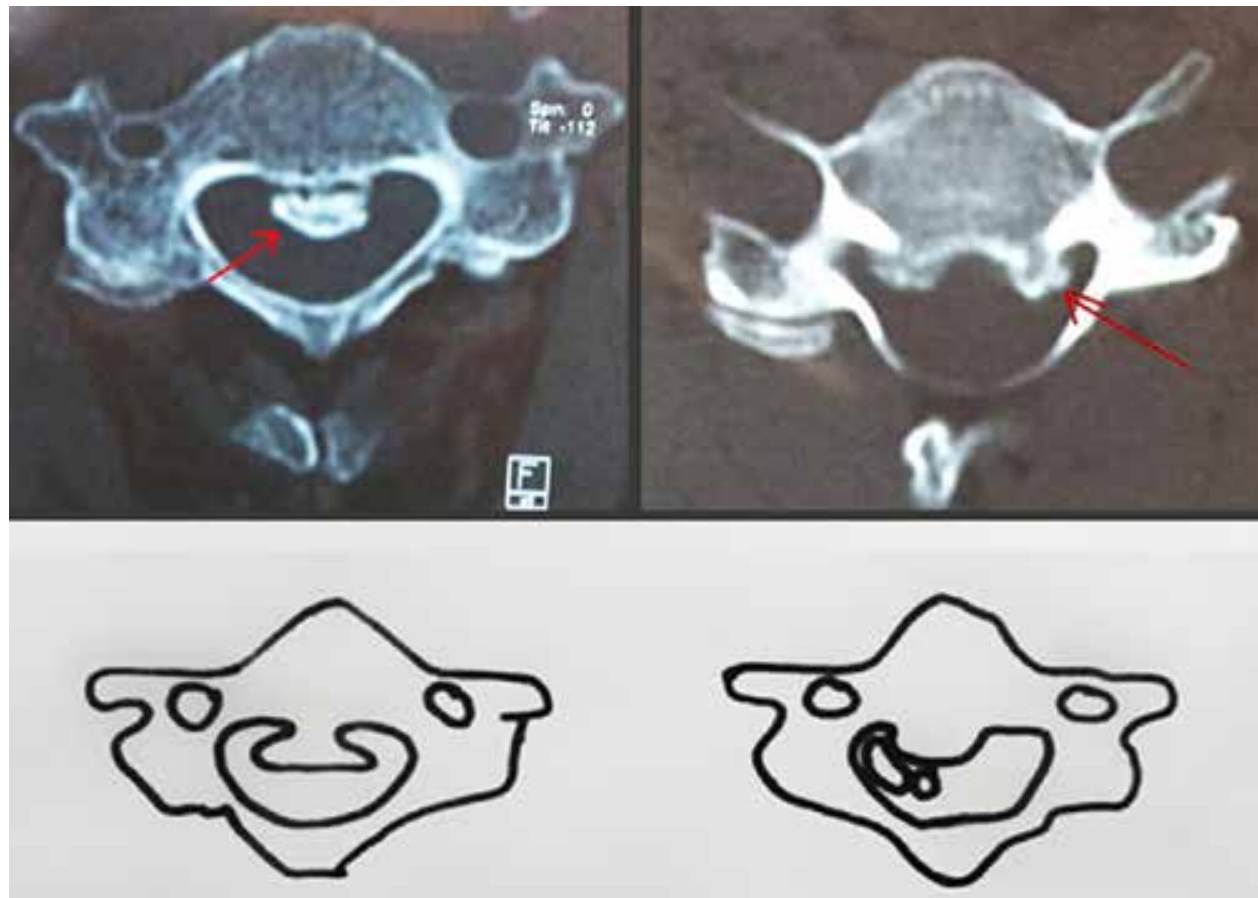

Şekil 4. Santral ve yana kaymış tip OPLL.

\section{Doğal Seyri}

Bir kohort çalışmasında, PLLO'nun \%60'dan daha fazla spinal kanal stenozuna yol açtığı tüm hastalarda servikal miyelopati meydana geldiği gösterilmiştir. PLLO'daki miyelopatinin ana nedeni, spinal korda statik kompresyon olmasına rağmen, radyolojik bulgularla klinik olarak nörolojik defisit arasında her zaman korelasyon olmamasıdır. ${ }^{[24,26]}$ Doğal seyirle ilgili bir başka klinik çalışmada; 10 yıldan fazla takip edilen 207 hastanın \%66'sında semptomatik değişiklik olmazken, \%16'sında miyelopati geliştiği belirtilmiştir. ${ }^{[27]}$ 
Servikal bölgede şiddetli spinal stenozu ve ileri düzeyde eklem hareket kısıtlılığı görülen olgularda, her zaman miyelopati gelişmeyebilir. Bu da, statik kompresyonun sadece miyelopatiye yol açmadığının bir göstergesidir. Listezis ve hipermobilite gibi dinamik faktörler de, özellikle mikst ve segmental PLLO'da, miyelopati gelişiminde önemli rol oynamaktadır. ${ }^{[28]}$

PLLO sonucu oluşan servikal kanal darlı̆̆ı, minör travmalar sonrası bile spinal kord hasarı gelişmesine yol açabilmektedir. Bir çalışmada, PLLO olan 106 hastada travma sonucu servikal spinal kord hasarı gelişmiştir. Bu hastaların \%88,7'sinde, eşlik eden kırık olmadan santral kord sendromu görülmüştür. Hastaların \%74'ünde travma, basit düşme ile gerçekleşmiştir. ${ }^{[29]}$

Hafif ve orta şiddette semptomatik ve şikayetlerin ilerlemediği hastalarda, non-steroid anti-inflamatuvar ilaç (NSAii)lar, antidepresanlar, antikonvülzanlar, opioidler, yatak istirahati, bölgesel stabilizasyon açısından breysler ve gözlem yeterli olabilir. Miyelopati gelişen hastalarda ve konservatif tedaviden yanıt alınamayan ilerleyici semptomları olanlarda, cerrahi tedavi tercih edilmelidir. Cerrahi tedavinin şekli; miyelopatinin şiddetine, ossifikasyonun içerdiği segmentin sayı, yer ve şiddetine, boyunun sagittal balansına, instabilitenin varlığına ve cerrahın tecrübesine göre değişiri. ${ }^{30]}$

\section{KAYNAKLAR}

1. Tauchi R, Lee SH, Peters $C$, Imagama S, Ishiguro $N$, Riew KD. Cervical Myeloradiculopathy due to Ossification of the Posterior Longitudinal Ligament with versus without Diffuse Idiopathic Spinal Hyperostosis. Global Spine J 2016;6(4):350-6. Crossref

2. Lee $N$, Yoon DH, Kim KN, Shin HC, Shin DA, HaY. Compression Angle of Ossification of the Posterior Longitudinal Ligament and Its Clinical Significance in Cervical Mylepathy. J Korean Neurosurg Soc 2016;59(5):471-7. Crossref

3. Singhatanadgige $W$, Limthongkul $W$, Valone $F$, Yingsakmongkol W, Riew KD. Outcomes following Laminoplasty or Laminectomy and Fusion in Patients with Myelopathy Caused by Ossification of the Posterior Longitudinal Ligament: A Systematic Review. Global Spine J 2016;6(7):702-9. Crossref

4. Lei T, Wang H, Tong T, Ma Q, Wang L, Shen Y. Enlarged anterior cervical discectomy and fusion in the treatment of severe localised ossification of the posterior longitudinal ligament. J Orthop Surg Res 2016;11(1):129. Crossref

5. Yoshii T, Sakai K, Hirai T, Yamada T, Inose H, Kato T, Enomoto M, Tomizawa S, Kawabata S, Arai Y, Okawa A. Anterior decompression with fusion versus posterior decompression with fusion for massive cervical ossification of the posterior longitudinal ligament with a $\geq 50 \%$ canal occupying ratio: a multicenter retrospective study. Spine J 2016;16(11):1351-7. Crossref

6. Kobashi G, Washio M, Okamoto K, Sasaki S, Yokoyama T, Miyake Y, Sakamoto N, Ohta K, Inaba Y, Tanaka H; Japan Collaborative Epidemiological Study Group for Evaluation of Ossification of the Posterior Longitudinal Ligament of the Spine Risk. High body mass index after age 20 and diabetes mellitus are independent risk factors for ossification of the posterior longitudinal ligament of the spine in Japanese subjects: a case-control study in multiple hospitals. Spine (Phila Pa 1976) 2004;29(9):1006-10.

7. Akune T, Ogata N, Seichi A, Ohnishi I, Nakamura K, Kawaguchi $\mathrm{H}$. Insulin secretory response is positively associated with the extent of ossification of the posterior longitudinal ligament of the spine. J Bone Joint Surg Am 2001;83-A(10):1537-44.

8. Shingyouchi $Y$, Nagahama A, Niida M. Ligamentous ossification of the cervical spine in the late middle-aged Japanese men. Its relation to body mass index and glucose metabolism. Spine (Phila Pa 1976) 1996;21(21):2474-8.

9. Kawamura $\mathrm{T}$, Kinoshita $\mathrm{M}$, Katsushima $\mathrm{S}$, Tokiguchi $\mathrm{S}$. Myotonic dystrophy with transverse myelopathy caused by ossification of the posterior longitudinal ligament-report of two cases. Rinsho Shinkeigaku 1986;26(4):387-94.

10. Bussiere JL, Ristori JM, Miravet L, Piat C, Soubrier M, Bardin $\mathrm{T}$. Vitamin resistant hypophosphatemic rickets and spinal cord compression. Apropos of 2 cases. Rev Rhum Ed Fr 1993;60(1):64-8

11. Chang F, Li L, Gao G, Ding S, Yang J, Zhang T, Zuo G. Role of Runx2 polymorphisms in risk and prognosis of ossification of posterior longitudinal ligament. J Clin Lab Anal 2016. [Epub ahead of print] Crossref

12. Nakajima M, Kou I, Ohashi H; Genetic Study Group of the Investigation Committee on the Ossification of Spinal Ligaments, Ikegawa S. Identification and Functional Characterization of RSPO2 as a Susceptibility Gene for Ossification of the Posterior Longitudinal Ligament of the Spine. Am J Hum Genet 2016;99(1):202-7. Crossref

13. Shi L, Cai G, Shi J, Guo Y, Chen D, Chen D, Yang $H$. Ossification of the posterior ligament is mediated by osterix via inhibition of the $\beta$-catenin signaling pathway. Exp Cell Res 2016;349(1):53-9. Crossref

14. Uchida K, Yayama T, Cai HX, Nakajima H, Sugita D, Guerrero AR, Kobayashi S, Yoshida A, Chen KB, Baba H. Ossification process involving the human thoracic ligamentum flavum: role of transcription factors. Arthritis Res Ther 2011;13(5):R144. Crossref

15. Nakajima M, Takahashi A, Tsuji T, Karasugi T, Baba H, Uchida K, Kawabata S, Okawa A, Shindo S, Takeuchi K, Taniguchi Y, Maeda S, Kashii M, Seichi A, Nakajima H, Kawaguchi Y, Fujibayashi S, Takahata M, Tanaka T, Watanabe K, Kida K, Kanchiku T, Ito Z, Mori K, Kaito T, Kobayashi S, Yamada K, Takahashi M, Chiba K, Matsumoto M, Furukawa K, Kubo M, ToyamaY. Genetic Study Group of Investigation Committee on Ossification of the Spinal Ligaments, Ikegawa S. A genom-wide association study identifies susceptibility loci for ossification of the posterior longitudinal ligament of the spine. Nat Genet 2014;46(9):1012-6. Crossref

16. Mizuno J, Nakagawa H. Ossified posterior longitudinal ligament: management strategies and outcomes. The Spine J 2006;6(6 Suppl):282S-8S. Crossref

17. Matsunaga S, Sakou T. OPLL. disease entity, incidence, literature search and prognosis. In: Yoneobu K, Nakamura K, Toyama Y, editors. OPLL. Ossification of the Posterior Longitudinal Ligament, 2nd ed. Tokyo, Japan: Springer; 2006. p.11-7.

18. Fujimori $T$, Watabe $T$, Iwamoto $Y$, Hamada $S$, Iwasaki $M$, Oda T. Prevalence, Concomitance And Distribution Of Ossification Of The Spinal Ligaments. Results Of Whole Spine CT Scans in 1500 Japanese Patients. Spine (Phila Pa 1976) 2016;41(21):1668-76. Crossref 
19. Schuenke M, Schulte E, Schumacher U. THIEME Atlas of Anatomy. General Anatomy and Musculoskeletal System, 1st ed. Stuttgart: Thieme; 2010. p.76-117.

20. Şenköylü A, Cheung KMC, Luk KDK. Servikal Myelopati. İçinde: Altun N, Yazar T, Benli iT, editörler. Dejeneratif Omurga Hastalıkları. Ankara: Rekmay Yayıncılık; 2016. p.293-4.

21. Palaoğlu S. Servikal spondiloz ve radikülomyelopati. İçinde: Aksoy K, Palaoğlu S, Pamir N, Tuncer R, editörler. Temel Nöroşirürji Cilt II. Ankara: Buluş Tasarım ve Matbaacılık Hizmetleri; 2005. p.1033-4.

22. Hirabayashi K, Bohlman HH. Multilevel cervical spondylosis. Laminoplasty versus anterior decompression. Spine (Phila Pa 1976) 1995;20(15):1732-4.

23. Mizuno J, Nakagawa $H$, Matsuo N, Song J. Dural ossification associated with servikal ossification of the posterior longitudinal ligament: frequency of dural ossification and comparison of neuroimaging modalities in ability to identify the disease. J Neurosurg Spine 2005;2(4):425-30. Crossref

24. Matsunaga S, Nakamura K, Seichi A, Yokoyama T, Toh S, Ichimura S, Satomi K, Endo K, Yamamoto K, Kato Y, Ito T, Tokuhashi Y, Uchida K, Baba H, Kawahara N, Tomita K, Matsuyama $\mathrm{Y}$, Ishiguro N, Iwasaki M, Yoshikawa $\mathrm{H}$, Yonenobu K, Kawakami M, Yoshida M, Inoue S, Tani T, Kaneko K, Taguchi T, Imakiire T, Komiya S. Radiographic predictors for the development of myelopathy in patients with ossification of the posterior longitudinal ligament: a multicenter cohort study. Spine (Phila Pa 1976) 2008;33(24):2648-50. Crossref
25. Matsunaga S, Kukita M, Hayashi K, Shinkura R, Koriyama C, Sakou T, Komiya S. Pathogenesis of myelopathy in patients with ossification of the posterior longitudinal ligament. J Neurosurg 2002;96(2 Suppl):168-72.

26. Choi BW. Clinical and Radiological Characteristics of Ossification of the Posterior Longitudinal Ligament of the Cervical Spine in Patients without Myelopathy: Results of a 1-year Pilot Study. Turk Neurosurg 2015. Crossref

27. Matsunaga S, Sakou T, Taketomi E, Yamaguchi M, Okano T. The natural course of myelopathy caused by ossification of the posterior longitudinal ligament in the cervical spine. Clin Orthop Relat Res 1994;(305):168-77.

28. Matsunaga S, Sakou T, Taketomi E, Komiya S. Clinical course of patients with ossification of the posterior longitudinal ligament: a minimum 10-year cohort study. J Neurosurg 2004;100(3 Suppl Spine):245-8.

29. Chikuda H, Seichi A, Takeshita K, Matsunaga S, Watanabe M, Nakagawa Y, Oshima K, Sasao Y, Tokuhashi Y, Nakahara S, Endo K, Uchida K, Takahata M, Yokoyama T, Yamada K, Nohara Y, Imagama S, Hosoe H, Ohtsu H, Kawaguchi H, Toyama Y, Nakamura K. Acute cervical spinal cord injury complicated by preexisting ossification of the posterior longitudinal ligament: a multicenter study. Spine (Phila Pa 1976) 2011;36(18):1453-8. Crossref

30. Choi BW, Song KJ, Chang H. Ossification of posterior longitudinal ligament: a review of literature. Asian Spine J 2011;5(4):267-76. Crossref 